\title{
'I do not know when I will practise again'
}

\author{
By Simon Threadgill, BDJ reader panel, County Durham
}

$\mathrm{P}$ rior to lockdown I was a dentist working out my notice at a practice in Chester Le Street, County Durham.

Since its emergence in China I have followed this outbreak via news apps and for the month leading up to lockdown via a website which gave me updates on new cases and deaths in all countries. With a rising sense of panic I could see how bad it was getting, how out of control it was and how little was being done in the UK to limit its spread.

Two weeks prior to the CDO's belated announcement I was sufficiently worried to begin more stringent decontamination procedures with both my nurse and I wiping down all the surgery surfaces, chairs and door handles between patients and the OCD hand washing kicked in.

The weekend of the herd immunity debacle before the prime minister's Monday night speech to the nation and three days before the CDO's missive, I decided that working in a dental surgery - the close contact with patients' mouths combined with production of aerosols - was way too dangerous. We would be putting the health and lives of our team and patients at risk unnecessarily and would contribute to the transmission of a highly infectious virus.

Luckily my principal was of a similar mind and at a hastily convened Monday morning meeting we decided that practice policy would be no scaling or periodontal treatment with the ultrasonic, no drilling unless absolutely necessary and then under a rubber dam, routine exams to be cancelled especially for vulnerable groups and to move to an emergency service only. I was happy that my principal instituted these measures as I know a lot of practices carried on as normal even into the next week. In hindsight though, I wonder if we as a profession should have shut up shop a lot earlier.

By the Friday my anxiety levels about catching and/or spreading coronavirus were through the roof, especially as I am an asthmatic. I had already read horror stories about how the pneumonia affected asthmatic lungs and had been frantically sourcing a nebuliser on Amazon. My principal very kindly at this juncture agreed I should go home and begin self-isolation.

So here I am two or is it three weeks later? I have no job and no income. As far as I am aware I am not eligible for any help from the government and I am worried that if financial help does become available I will have to risk my health and life and accept redeployment in a COVID hospital doing what I am not exactly sure, without the correct PPE. I would like to carry on as a dentist but there are no dental hubs set up yet. I have cancelled my indemnity and have begun to apply for jobs as a delivery driver or a 111 call centre operator. The small hope I had that the CDO would be able to clarify the situation was dashed during her webinar. At the end of it I was left feeling confused, depressed and fearful for the future of dentistry. I do not know when I will practise again or if I will be safe to practise again. It is a total mess.

\section{Online resource created to support redeployed dentists}

Dr Hesham Emam and Dr Vinita Shekar, dentists who work in hospital oral and maxillofacial surgery (OMFS) departments, have built an online resource to offer support and advice for hospital dentists who are, or who soon will be, working on the frontline of care in the COVID-19 (coronavirus) pandemic across the four nations: https://www.baoms.org.uk/professionals/advice_for_ dentists_working_in_covid_areas.aspx.

Dr Hesham Emam said: 'Hospital dentists like myself and Vinita usually provide surgical treatment for patients' mouths. With our specialty association, the British Association of Oral and Maxillofacial Surgeons (BAOMS), we have written some advice and collected some material and links that we hope will help our dental colleagues when they join the teams caring for COVID patients.'

BAOMS Chair Patrick Magennis added: 'All members of our OMFS departments have to deliver important emergency care for our own OMFS patients, and also contribute to the general COVID workload. This makes OMFS consultants nervous, and we are all medically as well as dentally qualified. Our SAS and trust grade staff are all singly qualified dentists working in a medical environment. It is important that BAOMS offers support.'

Dr Vinita Shekar, who represents SAS grades in BAOMS and at the Royal College of Surgeons of England, said: 'Dentists across the UK, some who work in hospitals and some from dental practice, are willing to do this work. They will be providing care well outside their normal clinical comfort zone. Hesham, myself and all the BAOMS Associate Fellows have built this web resource and are offering to be there for our dental colleagues, to offer support and advice. They need to keep safe, and remember we are all in this together and we are with them all the way.'

BAOMS President Rob Bentley, Consultant Craniofacial and Oral and Maxillofacial Surgeon, said: 'BAOMS has issued important advice for SAS and NHS trust dentists to see and treat only emergencies and, when they do, to wear the correct PPE. Most SAS grades are able to act on this advice, although a few have difficulty getting the better FFP3 masks. But they are also being asked to help outside OMFS departments in wards and on ITUs because everyone in the NHS has to contribute in this crisis. They have our support.' 